\title{
Aluminum Powder Preparation for Additive Manufacturing Using Electrostatic Classification
}

\author{
Alexander S. Shinkaryov ${ }^{1}{ }^{(D)}$, Margarita V. Cherkasova ${ }^{2}$, Ivan A. Pelevin ${ }^{1}$, Dmitriy Yu. Ozherelkov ${ }^{1}{ }^{(D,}$, \\ Stanislav V. Chernyshikhin ${ }^{3}$, Natalia A. Kharitonova ${ }^{1}$, Alexander A. Gromov ${ }^{1}$ (D) and Anton Yu. Nalivaiko ${ }^{1, *(D)}$ \\ 1 Catalysis Lab, National University of Science and Technology MISIS, 119991 Moscow, Russia; \\ shinkaryov@gmail.com (A.S.S.); i.pelevin@misis.ru (I.A.P.); d.ozherelkov@gmail.com (D.Y.O.); \\ nx-omd@mail.ru (N.A.K.); a.gromov@misis.ru (A.A.G.) \\ 2 Scientific Department, Research \& Engineering Corporation Mekhanobr-Tekhnika, \\ 199106 Saint Petersburg, Russia; tallyla@mail.ru \\ 3 Center for Design, Manufacturing and Materials, Skolkovo Institute of Science and Technology, \\ 121205 Moscow, Russia; stanislav.chernyshikhin@skoltech.ru \\ * Correspondence: nalivaiko@misis.ru; Tel.: +7-(495)-955-01-37
}

\section{check for} updates

Citation: Shinkaryov, A.S.; Cherkasova, M.V.; Pelevin, I.A.; Ozherelkov, D.Y..; Chernyshikhin, S.V.; Kharitonova, N.A.; Gromov, A.A.; Nalivaiko, A.Y.. Aluminum Powder Preparation for Additive Manufacturing Using Electrostatic Classification. Coatings 2021, 11, 629. https://doi.org/10.3390/coatings 11060629

Academic Editor: Chang-Hwan Choi

Received: 23 April 2021

Accepted: 22 May 2021

Published: 24 May 2021

Publisher's Note: MDPI stays neutral with regard to jurisdictional claims in published maps and institutional affiliations.

Copyright: (c) 2021 by the authors. Licensee MDPI, Basel, Switzerland. This article is an open access article distributed under the terms and conditions of the Creative Commons Attribution (CC BY) license (https:// creativecommons.org/licenses/by/ $4.0 /$ )

\begin{abstract}
This work aims to study the possibility of using an electrostatic drum-type separator to prepare a powder with a narrow size distribution curve for usage in additive manufacturing. The size distributions of the uncoated commercial aluminum powders ASP-30, ASP-22, and ASP-5 were analyzed. It was shown that the powders ASP-30 and ASP-22 have similar asymmetric distributions with a SPAN of 1.480 and 1.756, respectively. ASP-5 powder, in turn, has a narrow distribution with a SPAN of 0.869. ASP-30 powder was chosen for further experiment because, traditionally, separators are used to classify large-sized materials with particle size more than $100 \mu \mathrm{m}$. The optimal mode of electrostatic classification was proposed for the selected powder. Various classification methods, including centrifugal and electrostatic, were compared. The powders before and after classification were studied by XRD, SEM, TEM, and TG-DSC analyses. The obtained results showed that electrostatic classification does not lead to the formation of coatings on the processed powders. Electrostatic separation effectively narrows the particle size distribution, making it a suitable and valuable method to classify initial powders for additive manufacturing.
\end{abstract}

Keywords: aluminum powder; electrostatic classification; alumina; coating; oxide layer; additive manufacturing; selective laser melting; laser powder bed fusion

\section{Introduction}

Additive manufacturing is a breakthrough technology that has key advantages over traditional manufacturing technologies. The main advantage of additive manufacturing processes is creating products with complex geometry, which is impossible to achieve by other production methods. It reduces material consumption and allows making products with bio- and nature-inspired shapes for better performance.

Selective laser melting (SLM) is also referred to as laser powder bed fusion (LPBF) or bed deposition [1-7] because melting takes place on the printing bed. Such material as aluminum is preferable for additive manufacturing [8-15] due to its high strength and low density. It is perfectly suitable for applications demanding durable parts with low weight, such as aerospace and automotive industries [16,17].

Feedstock material quality is critical for obtaining high-level mechanical properties of aluminum parts produced by additive manufacturing. Literature analysis shows that the powder characteristics affect the properties and quality of printed parts [18-25]. The narrow size distribution of aluminum powder particles allows the production of parts with better mechanical properties. For aluminum powder material printing, specific requirements should be considered: purity of chemical composition, spherical shape (for 
better flowability), narrow fractional composition with the absence of large agglomerations, and the absence of moisture and gases in the powder [26,27]. Storage of aluminum powders and any further treatment in "open-air" conditions may increase water content in powder, resulting in changing conditions of powder spreading on the printing table. Powder material feeding and spreading on the printing table depend on the size distribution itself, the water content, and the surface energy of material samples. The study [21] showed that small particles in the powder batch increase the moisture sorption and the amount of surface energy. This results in greater interparticle bonding strength, which complicates the formation of uniform printing layers and can reduce printed sample properties. Moreover, the use of powders with a non-uniform particle diameter in the SLM process leads to voids in the powder layer (see Figure 1). Friable powder packaging leads to the formation of pores and cracks in the synthesized parts due to the impossibility of the particles' complete contact. In this regard, the investigation of new ways of preparation of the initial powders to ensure the best properties of 3D products is an urgent task.
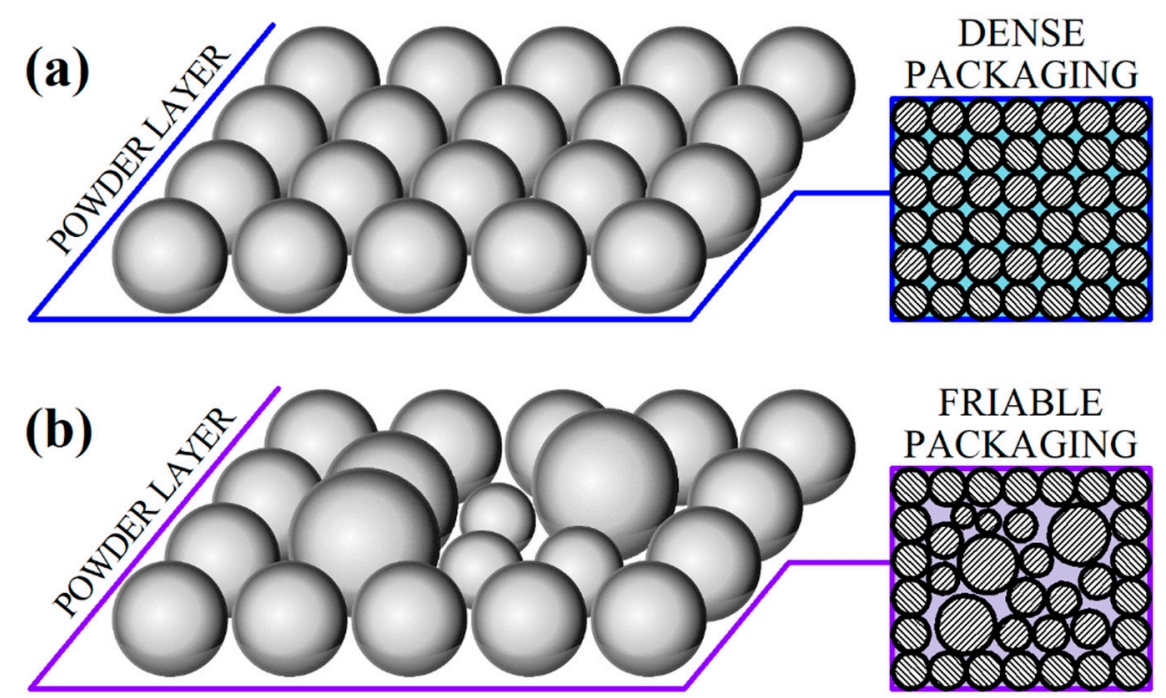

Figure 1. Formation of the powder building layer: (a) powder with a narrow particle size distribution; (b) powder with uneven particle size distribution.

In this work, uncoated powders of pure aluminum with different particle sizes were used. In certain publications, it was shown that powders with different size distributions behave differently $[19,20,28]$, and powders with a narrower range of particle sizes provide better flowability. In addition, it was concluded [21] that the narrow size distribution and the presence of spherical particles larger than $48 \mu \mathrm{m}$ lead to decreasing water sorption and surface energy characteristics, resulting in higher UTS and hardness of printed parts.

Magnetic separators cannot classify aluminum as it does not have magnetic properties, and it is usually classified by standard methods using sieves. Such a separation method is often used in all industrial enterprises producing aluminum powder, and it is effective only for large-scale production. In this paper, an alternative method for classifying aluminum powders was considered. A new method for classifying aluminum feedstock powders allowing separation of fine particles less than $100 \mu \mathrm{m}$ was described. The possibility of using the electrostatic classification method to obtain a powder with a narrow size distribution curve for the SLM process was investigated.

\section{Materials and Methods}

The uncoated powders of pure aluminum ASP-30, ASP-22, and ASP-5 produced by UC RUSAL (Moscow, Russia) were used in this work. These powders are classified by the manufacturer and named according to their D50 size (maximum particle size for 50\% of the cumulative mass): ASP-5 has D50 $=5 \mu \mathrm{m}$, and ASP-22 and ASP-30 powders have 
D50 $=22 \mu \mathrm{m}$ and $30 \mu \mathrm{m}$, respectively. For the production of these powders, technical-grade aluminum $(99.7 \% \mathrm{Al})$ was used.

The particle size analysis of powder samples was carried out using a Microsizer 201C laser particle analyzer (VA Instalt Company, Saint Petersburg, Russia), including measurements of such size distribution characteristics as D50, D90, and D10. SPAN is a calculated parameter that determines the width of the particle size distribution. SPAN values were calculated based on these parameters according to the following equation $[20,28]$ :

$$
\mathrm{SPAN}=(\mathrm{D} 90-\mathrm{D} 10) / \mathrm{D} 50,
$$

where D10 is the maximum particle size for $10 \%$ of the cumulative mass, $\mu \mathrm{m}$; D50, the maximum particle size for $50 \%$ of the cumulative mass, $\mu \mathrm{m}$; and D90, the maximum particle size for $90 \%$ of the cumulative mass, $\mu \mathrm{m}$.

The research was carried out using ELKOR (Mekhanobr-Tekhnika REC, Saint Petersburg, Russia) and Zeus (Mekhanobr-Tekhnika REC, Saint Petersburg, Russia) drum-type electrostatic separators (see Figure 2) [29].

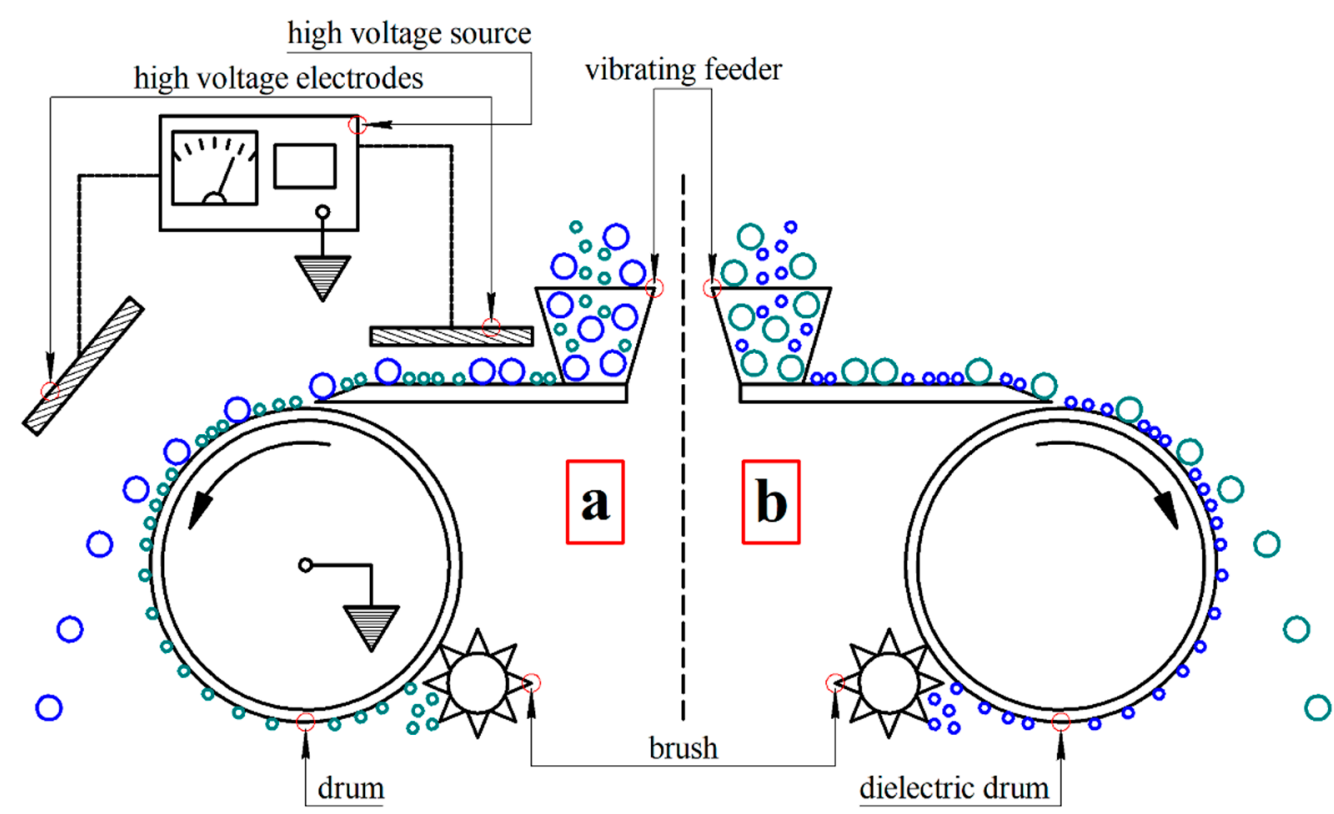

Figure 2. Separator schemes: (a) ELKOR electrostatic drum separator; (b) Zeus centrifugal drum separator.

A distinctive feature of the electrostatic classification process is that the separation depends not only on the physical properties of the particles but also on the method of acquiring an electric charge. Separators were functioning in the air without shielding gases. That is why there was a possibility of increasing the oxidation reaction rate under the electric discharge applied. Powder supply to the separation zone in this type of separator was designed with the vibration applied to feed the powder in the fluidization mode. The fundamental difference between Zeus and ELKOR models in this study lies in different drum configurations: the ELKOR separator has a metal grounded drum, and the Zeus separator has a completely dielectric drum. In ELKOR, a corona electrostatic charge is supplied to the separation area, and in Zeus, there is a possibility of supplying the charge directly to the material. In this study, a Zeus separator was used without applying charge, and the separation occurred due to the action of centrifugal force with a rotation speed of 100-300 rpm.

According to the operation principle of separator devices [30,31], the material is fed from the feed hopper to the vibrating feeder tray providing powder supply for preliminary separation of conglomerates from adhered fine particles. From the tray of the vibrating feeder, material enters the surface of the rotating drum (collecting electrode), which is 
carried to the corona discharge zone. In the corona discharge field, powder particles acquire a charge, which corresponds to the sign of the corona electrode charge. Under the action of electric forces, the powder is pressed against the surface of the drum by the so-called "mirror image forces." Larger particles are thrown off the drum by centrifugal force. The deflection electrode contributes to the change in the trajectory of particles leaving the drum. Fine particles release their charge more slowly and therefore settle on the drum. They are removed from the drum surface by a rotating brush into 10 trays of the unloading device located at the rear wall of the working chamber.

The XRD patterns of studied samples were obtained using a Difrey 401 X-ray diffractometer (Scientific Instruments Company, Saint Petersburg, Russia). Micrographs of the studied samples were taken using a Tescan VEGA3 scanning electron microscope (SEM) (TESCAN, Brno, Czech Republic) and a JEOL JEM-2100 transmission electron microscope (TEM) (JEOL, Tokyo, Japan. To assess the thickness of the oxide film using TEM, samples of aluminum powders were dehydrated in alcohols of increasing concentration (30\%, $50 \%, 70 \%, 96 \%$, and $100 \%$ ) and acetone. In the next step, the powders were pitched in an Araldite502 Kit epoxy resin with the addition of a DMP-30 catalyst. Sections were made on an Ultracut R Leica ultramicrotome. Thermogravimetry and differential scanning calorimetry (TG-DSC) analyses were performed using an SDT-Q600 thermal analyzer (TA Instruments, New Castle, DE, USA) in an air atmosphere with a $20^{\circ} \mathrm{C} / \mathrm{min}$ heating rate.

\section{Results and Discussion}

The characteristics of the particle size distribution for initial ASP-5, ASP-22, and ASP-30 powders are shown in Table 1, and particle size diagrams are depicted in Figure 3.

Table 1. Size distribution of the initial powder.

\begin{tabular}{cccc}
\hline Powder Type & ASP-30 & ASP-22 & ASP-5 \\
\hline D10 $(\mu \mathrm{m})$ & 9.8 & 6.9 & 3.0 \\
\hline D50 $(\mu \mathrm{m})$ & 28.0 & 21.9 & 4.9 \\
\hline D90 $(\mu \mathrm{m})$ & 51.4 & 45.4 & 7.3 \\
\hline SPAN & 1.480 & 1.756 & 0.869 \\
\hline
\end{tabular}

ASP-5 powder has a Gaussian-like particle size distribution with a small number of coarser particles included. According to Table 1, ASP-5 powder has a very narrow distribution with a SPAN of 0.869 , and there is no need to classify this powder.

During electrostatic separation, ASP-22 and ASP-5 powders (D50 $=21.9 \mu \mathrm{m}$ and $\mathrm{D} 50=4.9 \mu \mathrm{m}$, respectively) showed poor processability. These powders tend to agglomerate, and the vibrating feeder did not provide well pouring of such powders.

ASP-30 and ASP-22 powders have similar asymmetric distributions with a SPAN of 1.480 and 1.756, respectively. It was decided to experiment with only one powder and check the applicability of this method to the ASP-30 powder with larger particles (see Figure 4) because, traditionally, separators are used for classification materials with particle size more than $100 \mu \mathrm{m}[31,32]$. 


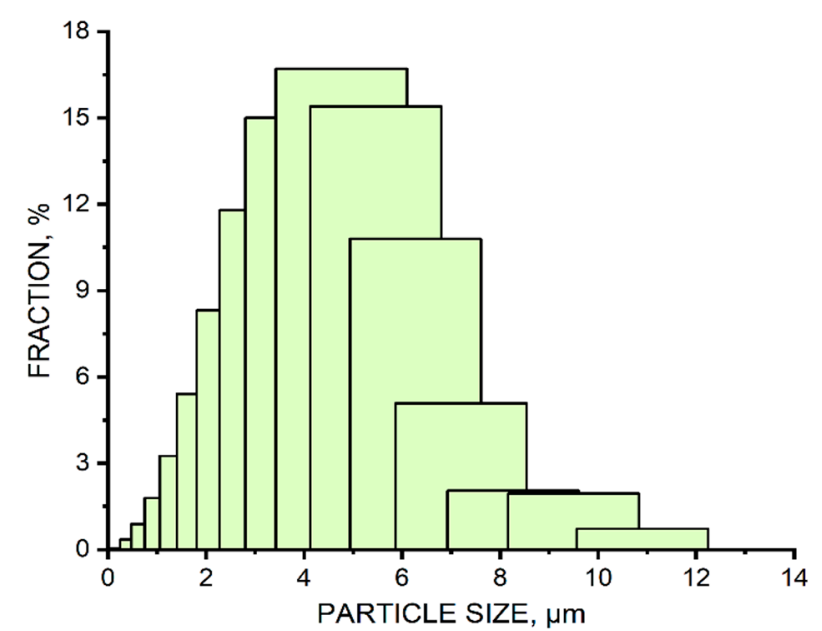

(a)

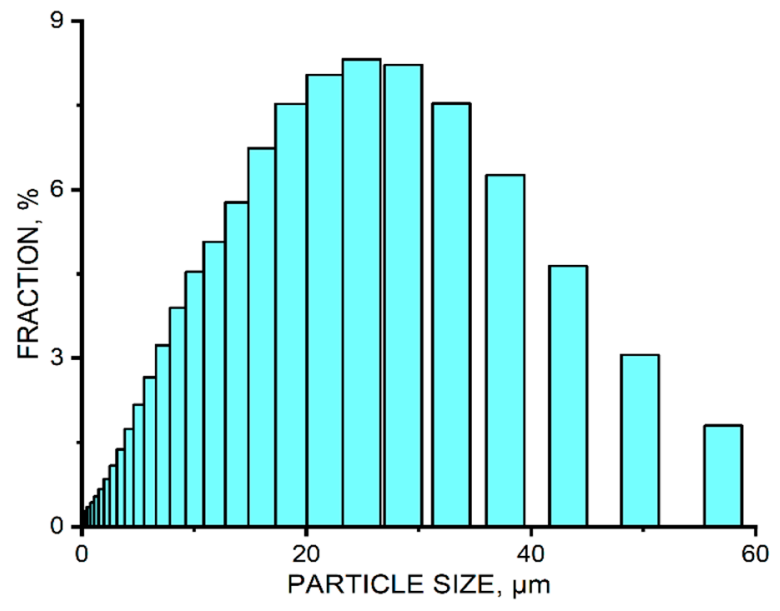

(b)

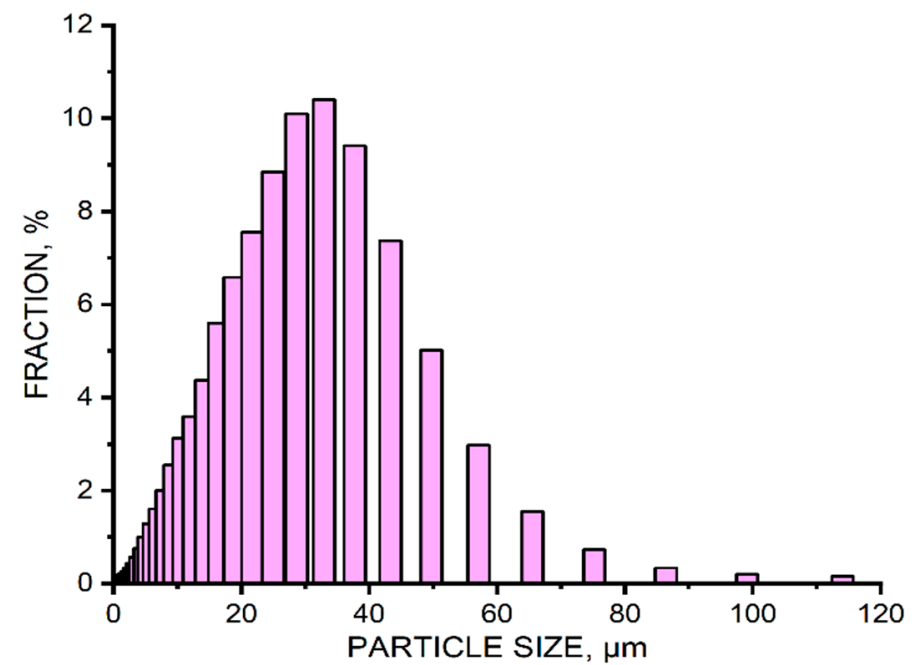

(c)

Figure 3. Particle size distribution of initial commercial powders: (a) ASP-5, (b) ASP-22, and (c) ASP-30.

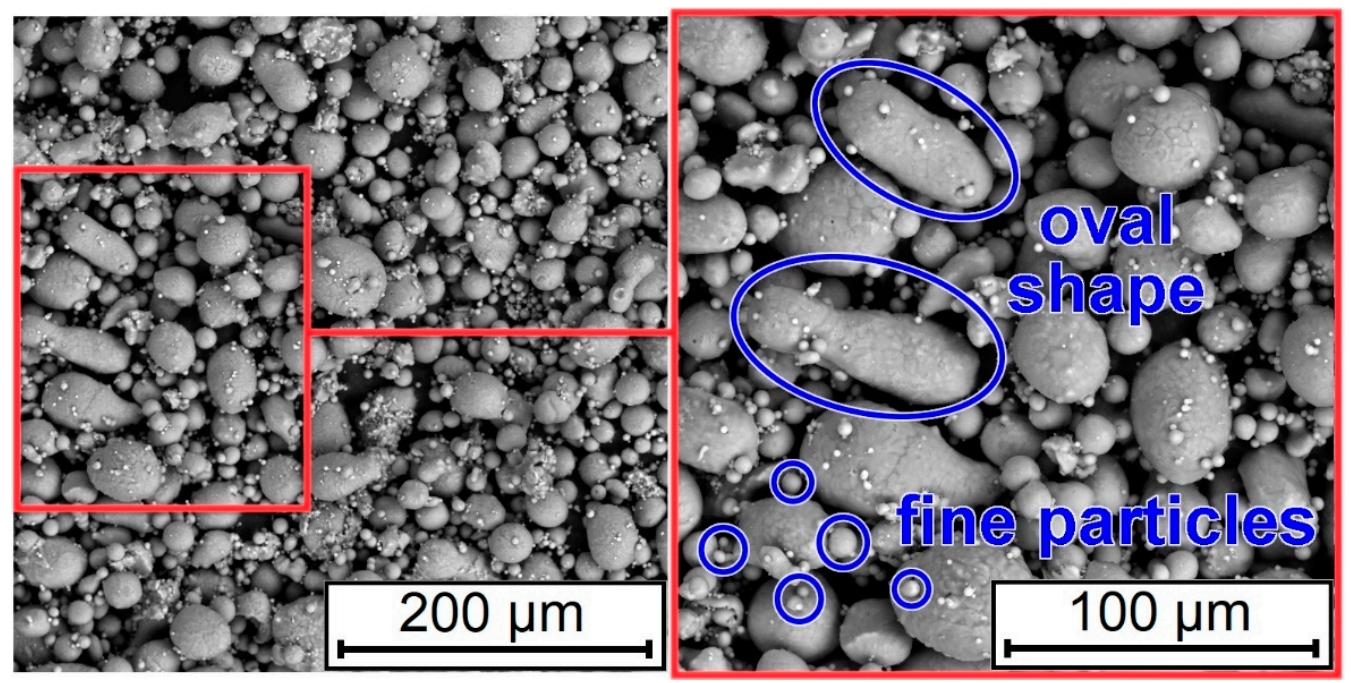

Figure 4. SEM images of ASP-30 powder before classification. 
The results of powder classification are shown in Tables 2 and 3. An ELKOR separator was used in the electrostatic mode, and as mentioned earlier, a Zeus separator was used as reference centrifugal separator without applying electrostatic discharge. It can be concluded from Table 2 that the $10 \mathrm{kV}$ operation mode led to inappropriate results while performance under $20 \mathrm{kV}$ was better, and in trays joined under number 3 , a relatively narrow distribution with a SPAN of 1.252 was obtained. The best achieved size distribution was obtained using the ELKOR separator in $30 \mathrm{kV}$ mode and was equal to 1.186, which is $19.9 \%$ better than the initial distribution.

Table 2. Size distribution of ASP-30 powder after separation using the ELKOR unit with different voltages.

30 kV Voltage Applied

\begin{tabular}{|c|c|c|c|c|}
\hline Tray number & 1 & 2 & 3 & 4 \\
\hline $\mathrm{D} 10(\mu \mathrm{m})$ & 10.0 & 17.1 & 6.09 & 15.6 \\
\hline $\mathrm{D} 50(\mu \mathrm{m})$ & 23.3 & 34.9 & 16.9 & 31.9 \\
\hline $\mathrm{D} 90(\mu \mathrm{m})$ & 46.9 & 58.5 & 36.4 & 54.1 \\
\hline SPAN & 1.584 & 1.186 & 1.794 & 1.207 \\
\hline \multicolumn{5}{|c|}{20 kV Voltage Applied } \\
\hline Tray number & 1 & 2 & 3 & 4 \\
\hline $\mathrm{D} 10(\mu \mathrm{m})$ & 13.30 & 12.5 & 14.4 & 9.7 \\
\hline $\mathrm{D} 50(\mu \mathrm{m})$ & 34.60 & 32.0 & 33.8 & 25.1 \\
\hline $\mathrm{D} 90(\mu \mathrm{m})$ & 58.60 & 56.3 & 56.7 & 47.00 \\
\hline SPAN & 1.309 & 1.369 & 1.252 & 1.485 \\
\hline \multicolumn{5}{|c|}{10 kV Voltage Applied } \\
\hline Tray number & 1 & 2 & 3 & 4 \\
\hline $\mathrm{D} 10(\mu \mathrm{m})$ & 10.4 & 11.2 & 10.9 & 9.7 \\
\hline $\mathrm{D} 50(\mu \mathrm{m})$ & 30.1 & 31.3 & 29.9 & 25.5 \\
\hline $\mathrm{D} 90(\mu \mathrm{m})$ & 55.5 & 55.4 & 53.9 & 47.3 \\
\hline SPAN & 1.498 & 1.412 & 1.438 & 1.475 \\
\hline
\end{tabular}

As shown in Table 3, the Zeus unit performed better with $200 \mathrm{rpm}$ and $300 \mathrm{rpm}$ rotation speeds, which in turn provided the best distribution results 1.297 and 1.276 in trays joined under number 2 (machine has 10 trays, not all of them were used and materials in two neighboring trays were joined under number 1). According to the results obtained after the classification of material using the separator with an applied electrostatic charge and without applied voltage, we can conclude that the best size distribution was obtained using the ELKOR separator with $30 \mathrm{kV}$ voltage. A comparison of the granulometric characteristics of the ASP-30 powder in the classification is presented in Table 4. The change in the particle size distribution (compared with Figure 3c) is shown in Figure 5. SEM images of ASP-30 powder after classification are shown in Figure 6. 
Table 3. Size distribution of ASP-30 powder after separation using the Zeus unit.

\begin{tabular}{|c|c|c|c|}
\hline \multicolumn{4}{|c|}{100 rpm Drum Rotation Speed } \\
\hline Tray number & 1 & 2 & - \\
\hline $\mathrm{D} 10(\mu \mathrm{m})$ & 10.6 & 11.1 & - \\
\hline $\mathrm{D} 50(\mu \mathrm{m})$ & 29.8 & 30.5 & - \\
\hline $\mathrm{D} 90(\mu \mathrm{m})$ & 54.4 & 55.2 & - \\
\hline SPAN & 1.470 & 1.446 & - \\
\hline \multicolumn{4}{|c|}{200 rpm Drum Rotation Speed } \\
\hline Tray number & 1 & 2 & 3 \\
\hline $\mathrm{D} 10(\mu \mathrm{m})$ & 11.9 & 13.1 & 9.6 \\
\hline $\mathrm{D} 50(\mu \mathrm{m})$ & 31.5 & 33.0 & 26.5 \\
\hline $\mathrm{D} 90(\mu \mathrm{m})$ & 54.9 & 55.9 & 49.2 \\
\hline SPAN & 1.365 & 1.297 & 1.493 \\
\hline \multicolumn{4}{|c|}{300 rpm Drum Rotation Speed } \\
\hline Tray number & 1 & 2 & 3 \\
\hline $\mathrm{D} 10(\mu \mathrm{m})$ & 11.1 & 13.9 & 8.4 \\
\hline $\mathrm{D} 50(\mu \mathrm{m})$ & 30.9 & 34.0 & 25.6 \\
\hline $\mathrm{D} 90(\mu \mathrm{m})$ & 54.7 & 57.3 & 49.5 \\
\hline SPAN & 1.411 & 1.276 & 1.604 \\
\hline
\end{tabular}

Table 4. Comparison of the initial ASP-30 powder characteristics with the best results of size distribution after using ELKOR and Zeus units.

\begin{tabular}{cccc}
\hline Separator Type & ELKOR & Zeus & $\begin{array}{c}\text { ASP-30 Powder } \\
\text { (Initial) }\end{array}$ \\
\hline Voltage applied & $30 \mathrm{kV}$ & No voltage & - \\
\hline $\mathrm{D} 10(\mu \mathrm{m})$ & 17.1 & 13.9 & 9.8 \\
\hline $\mathrm{D} 50(\mu \mathrm{m})$ & 34.9 & 34.0 & 28.0 \\
\hline $\mathrm{D} 90(\mu \mathrm{m})$ & 58.5 & 57.3 & 51.4 \\
\hline SPAN & 1.186 & 1.276 & 1.480 \\
\hline
\end{tabular}

Analysis of the SEM data (see Figures 4 and 6) and the laser particle analyzer data (see Figure 5) showed that the content of fine particles and the amount of large oblong particles in the powder after electrostatic classification significantly decreased. The processed powder mainly consisted of spherical or rounded particles of the same size $(30 \pm 10 \mu \mathrm{m})$. We can conclude that the nature of the distribution before and after classification has not changed, and the lognormal distribution law can be applied. The curves presented in Figure 5 are slightly beveled due to the initial spraying process with many varying parameters that influence the resulting sizes of powders. In the case of narrowing the powder distribution by electrostatic discharge, the center of the size curve moved from $28 \mu \mathrm{m}$ to $34.9 \mu \mathrm{m}$. 


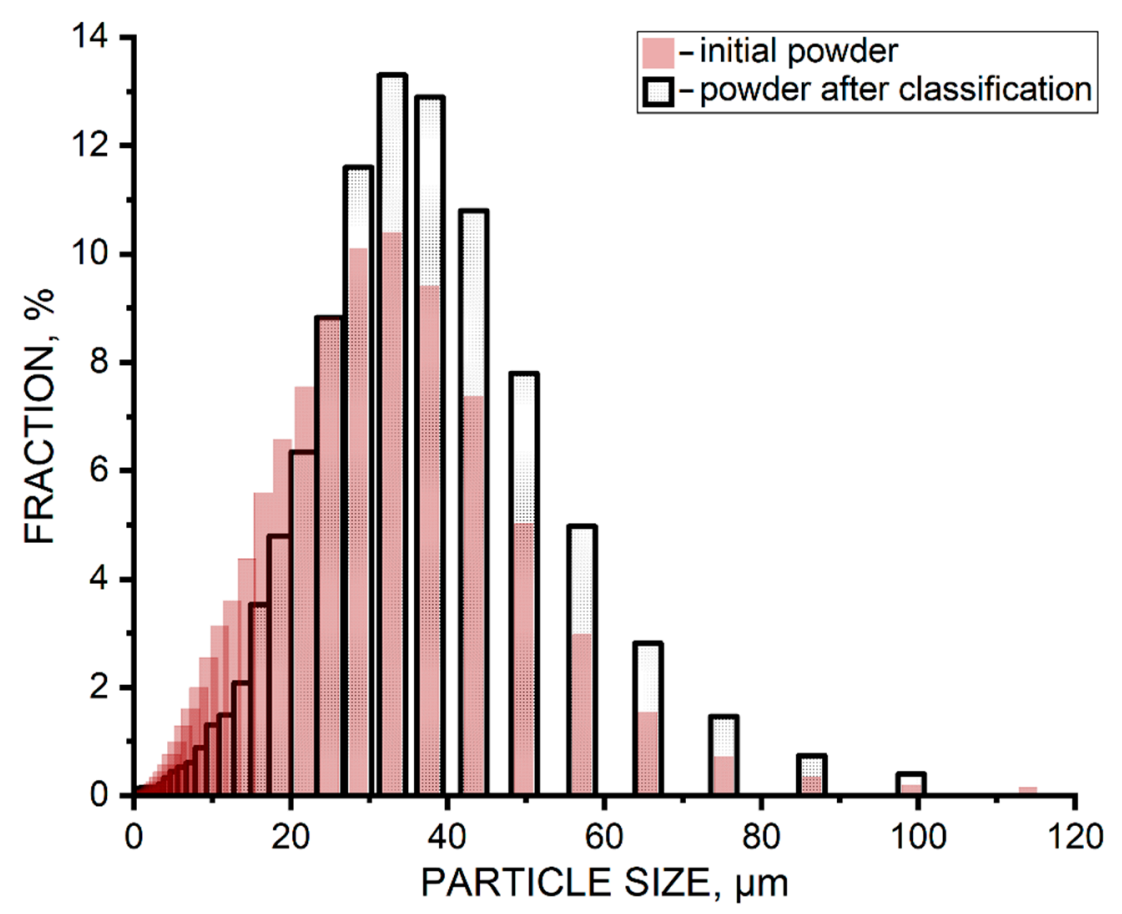

Figure 5. Particle size distribution comparison of ASP-30 powder.

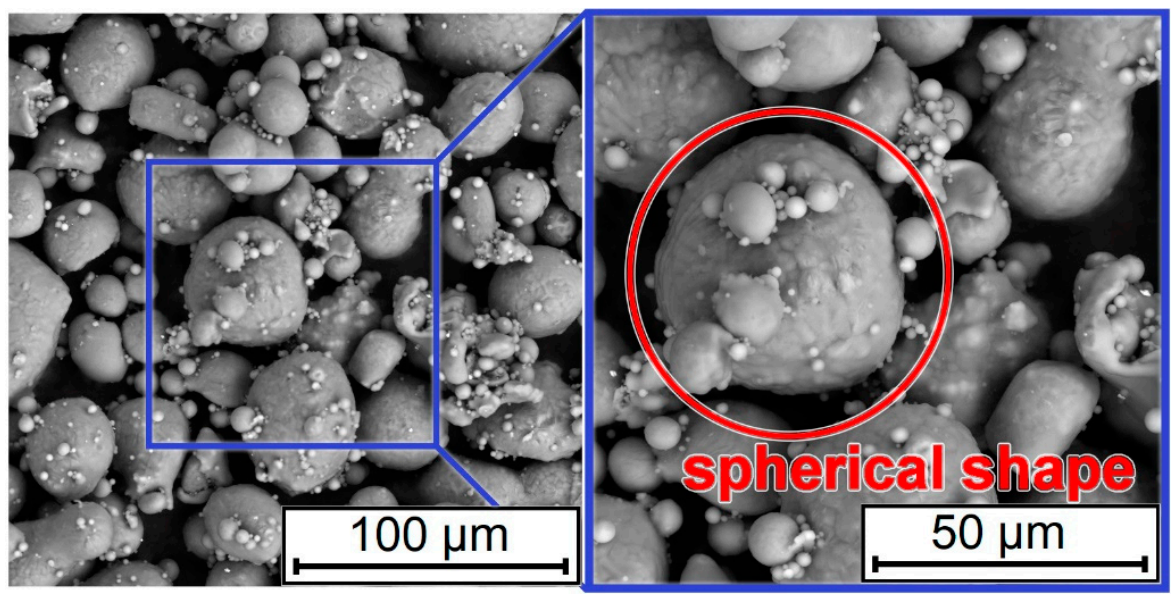

Figure 6. SEM images of ASP-30 powder after classification.

One of the important powder requirements for additive manufacturing is the absence of non-metallic or other coatings. The coating on the particles can reduce the processability of the powder due to the formation of a barrier layer that will prevent laser fusion of the particles. As is known, aluminum has a high affinity for oxygen [33]. As a rule, each particle of aluminum in any micron-size powder has a nanoscale layer of alumina, protecting the metal from further oxidation. The nanoscale layer of alumina is not a barrier for SLM aluminum powders since the laser beam's energy easily melts it. However, an increase in the thickness of the surface layer of alumina can disrupt the SLM process, which could lead to incorrect particle fusion or require the use of higher laser power. Based on this, the effect of electrostatic classification on the oxide layer thickness of the aluminum particles was studied.

XRD patterns of ASP-30 powder samples before and after electrostatic classification are shown in Figure 7. According to the results, both samples have similar spectra, which correspond to aluminum. Aluminum oxide (alumina) and other oxygen-containing aluminum compounds were not detected. 


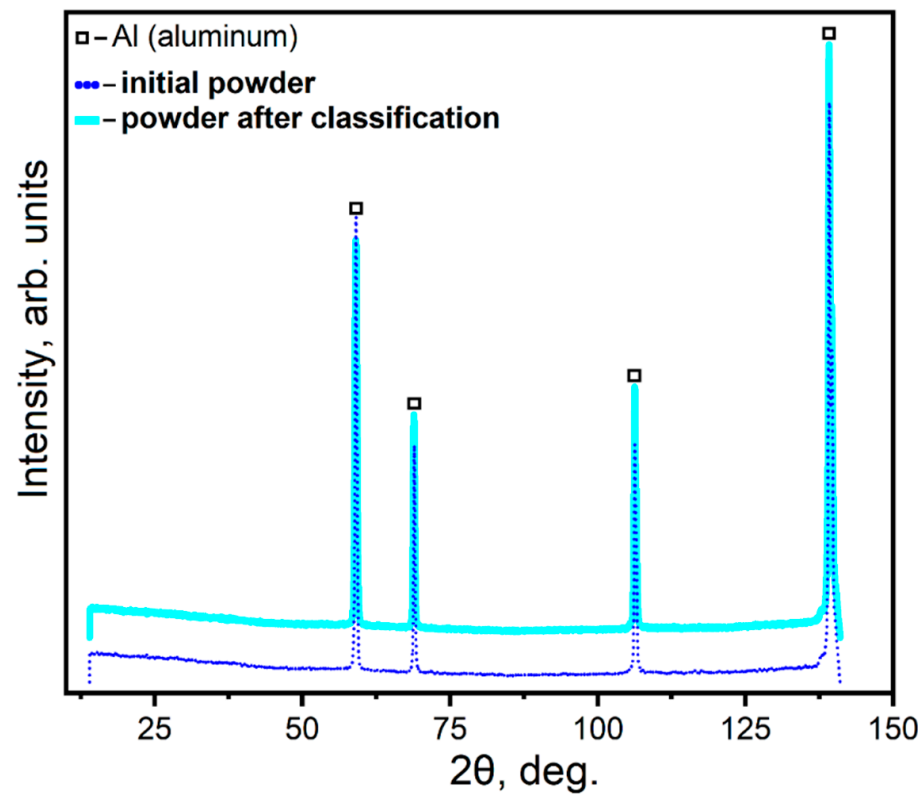

Figure 7. XRD results of ASP-30 powder before and after electrostatic classification.

As an additional research method, TG-DSC analysis (see Figure 8) was used to assess the presence of oxides in aluminum powder. The behavior of the resulting curves is identical. In both samples, the thermal effect (red line) is visible in the vicinity of $660^{\circ} \mathrm{C}$, associated with the transition of aluminum from the solid to the liquid state. A sharp fluctuation in the dynamics of weight change (blue line) at $600{ }^{\circ} \mathrm{C}$ is associated with the beginning of active oxidation of aluminum powder, which is also traced on the weight change curve (green line). In general, the TG-DSC data for ASP-30 powder before and after the electrostatic classification were very similar, which confirmed the absence of aluminum oxidation during the classification process.

Comparing the TEM images also confirms the absence of changes in the thickness of the oxide layer on the aluminum particles (see Figure 9). The oxide layer before and after the electrostatic classification was no more than $3 \mathrm{~nm}$.

Based on the presented set of analyses, it can be concluded that no significant oxidation occurred during the electrostatic classification. Thus, there are no obstacles in terms of changing the processability of powders for applying electrostatic separation to classify the initial powders used in additive manufacturing.

The ASP-30 powder studied had a wide particle size distribution, which was indicative of demonstrating classification capabilities and assessing the degree of "narrowing" of the particle distribution. The tested aluminum powder is close to the chemical composition of pure aluminum and has an electrostatic behavior similar to other aluminum alloys (for example, the AlSi10Mg alloy, widely used in additive manufacturing). Electrostatic charge value for such material particles can be described as the charge of the spherical electrostatic condenser with the electrons distributed along the surface of the particle's oxide layer. We can consider similar electrostatic charge values for pure aluminum and AlSi10Mg alloy in terms of our study. Thus, experimental results can also be applied for the electrostatic classification of aluminum alloys with close electrostatic characteristics.

We also examined the safety question of corona discharge application to aluminum, which could be easily initiated to combustion and could be dangerously explosive in case of small particles spraying in the air. Dielectric barrier discharge is preferable for classification due to minimizing the possibility of electrical breakdown between electrodes and metal powder dust through spark discharge. Dielectric barrier discharge occurs during the voltage applied to the electrodes, covered with the isolation dielectric layer. According to the publication [31], a positive example of such a principle was used to separate fine coal and fly ash. The ability of the dielectric barrier to eliminate electrical breakdown in 
the working area of the electrostatic separator was implemented by Mekhanobr Tekhnika Corporation in the design of triboelectrostatic separators.

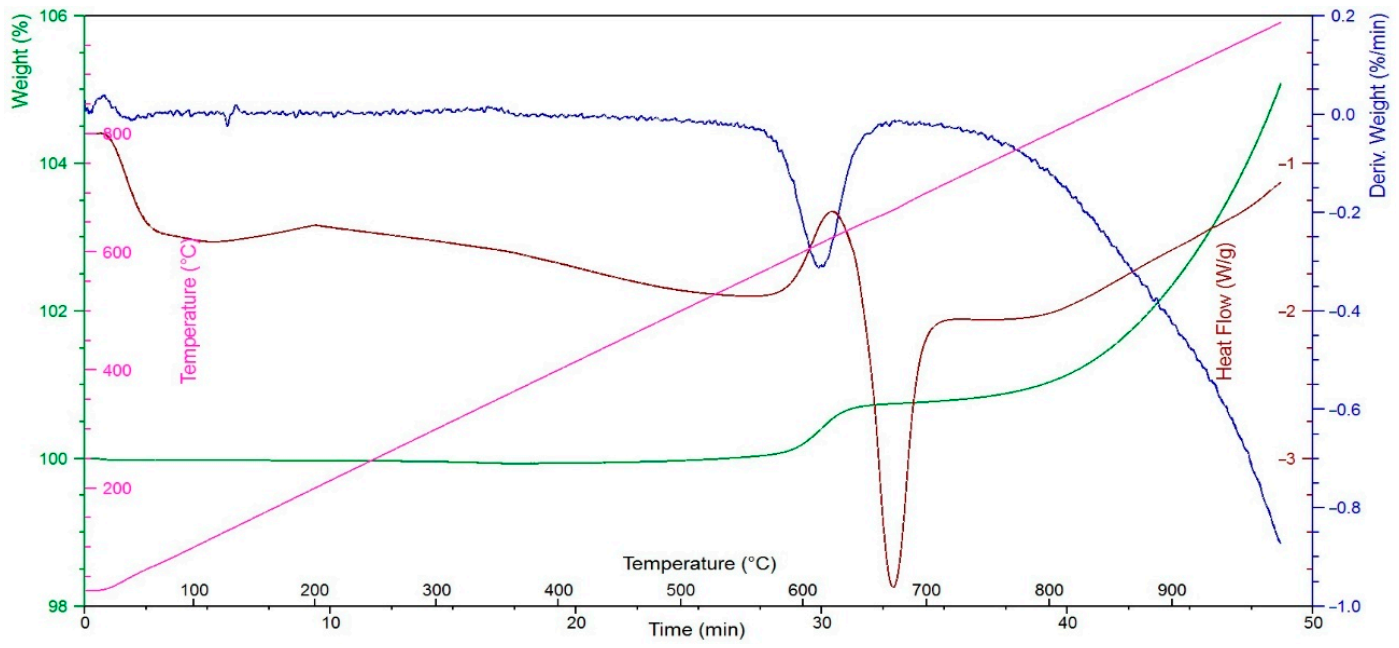

(a)

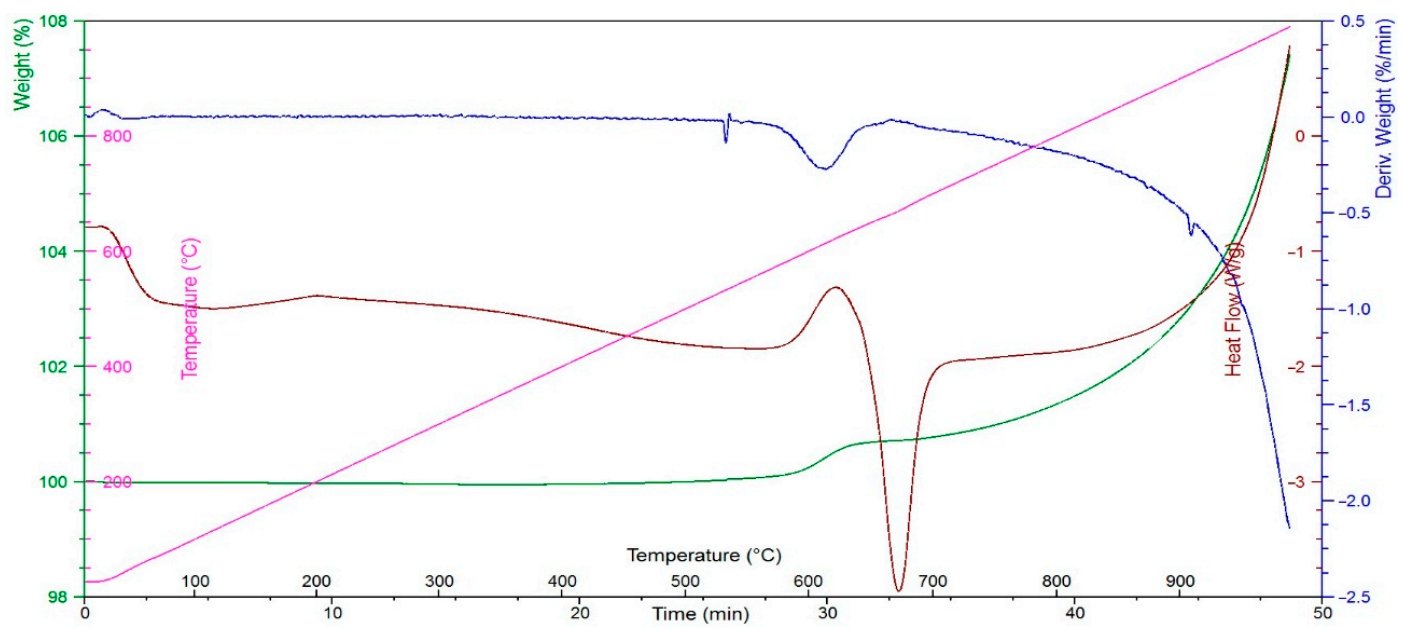

(b)

Figure 8. TG-DSC analysis of ASP-30 powder: (a) before electrostatic classification; (b) after electrostatic classification with $30 \mathrm{kV}$ voltage applied.

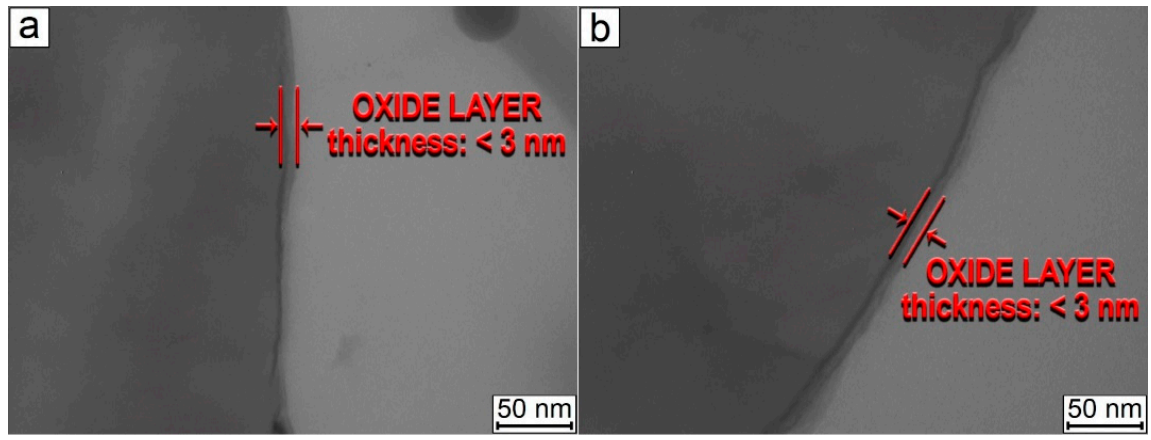

Figure 9. TEM images of ASP-30 powder: (a) before electrostatic classification; (b) after electrostatic classification with $30 \mathrm{kV}$ voltage applied. 


\section{Conclusions}

After initial analysis, it was shown that ASP-30 and ASP-22 powders have similar asymmetric distributions with a SPAN of 1.480 and 1.756, respectively. ASP-5 powder has a narrow distribution with a SPAN of 0.869 . ASP-5 powder showed poor processability during electrostatic separation due to agglomeration and insufficient flowability through a vibrating feeder. As electrostatic separators are typically used to classify powders with particles larger than $100 \mu \mathrm{m}$, it was applied to ASP-30 powder, which has a larger particle size and is easier to electrify by electrostatic discharge. Such a principle was proposed for the classification of powders with a larger D50 diameter.

Electrostatic separation showed better results than the centrifugal classification of powders. The Zeus unit performed better with $200 \mathrm{rpm}$ and $300 \mathrm{rpm}$ speeds, which gave the best distribution results with a SPAN of 1.297 and 1.276, respectively. The best size distribution was achieved with electrostatic discharge (ELKOR unit with $30 \mathrm{kV}$ applied voltage) and was equal to 1.186 , which is $19.9 \%$ narrower than the initial distribution. Thus, the implementation of the ELKOR separator gave better size distribution of aluminum powders after classification and could be beneficial for application.

The complex analysis (XRD, TG-DSC, and TEM) showed that the aluminum powder did not significantly oxidize after electrostatic classification, retaining the alumina surface layer of a few nanometers. A significantly narrower particle size distribution was obtained after electrostatic separation, demonstrating the possibility of application of electrostatic separators for powder classification in additive manufacturing. In terms of safety during the application of high voltage to aluminum powder, dielectric barrier discharge is preferable for classification due to the minimization of the possibility of electrical breakdown between the electrodes and the dust of fine metal particles.

Author Contributions: Conceptualization, A.S.S., M.V.C., and A.Y.N.; data curation, S.V.C. and N.A.K.; formal analysis, I.A.P., D.Y.O., and A.A.G.; investigation, A.S.S. and M.V.C.; methodology, M.V.C. and A.A.G.; supervision, A.Y.N. and A.A.G.; visualization, S.V.C. and N.A.K.; writingoriginal draft, A.S.S. and A.Y.N.; writing-review and editing, I.A.P. and D.Y.O. All authors have read and agreed to the published version of the manuscript.

Funding: The work was financially supported by the Russian Science Foundation (RSF), grant no.19-79-30025.

Institutional Review Board Statement: Not applicable.

Informed Consent Statement: Not applicable.

Data Availability Statement: The data presented in this study are available on request from the corresponding author. The data are not publicly available due to privacy.

Conflicts of Interest: The authors declare no conflict of interest.

\section{References}

1. Khairallah, S.A.; Anderson, A.T.; Rubenchik, A.; King, W.E. Laser powder-bed fusion additive manufacturing: Physics of complex melt flow and formation mechanisms of pores, spatter, and denudation zones. Acta Mater. 2016, 108, 36-45. [CrossRef]

2. Gu, D.; Meiners, W.; Wissenbach, K.; Poprawe, R. Laser additive manufacturing of metallic components: Materials, processes and mechanisms. Int. Mater. Rev. 2012, 57, 133-164. [CrossRef]

3. Debroy, T.; Wei, H.L.; Zuback, J.S.; Mukherjee, T.; Elmer, J.W.; Milewski, J.O.; Beese, A.M.; Wilson-Heid, A.; De, A.; Zhang, W. Additive manufacturing of metallic components-Process, structure and properties. Prog. Mater. Sci. 2018, 92, 112-224. [CrossRef]

4. Attar, H.; Calin, M.; Zhang, L.; Scudino, S.; Eckert, J. Manufacture by selective laser melting and mechanical behavior of commercially pure titanium. Mater. Sci. Eng. A 2014, 593, 170-177. [CrossRef]

5. Attar, H.; Ehtemam-Haghighi, S.; Kent, D.; Wu, X.; Dargusch, M.S. Comparative study of commercially pure titanium produced by laser engineered net shaping, selective laser melting and casting processes. Mater. Sci. Eng. A 2017, 705, 385-393. [CrossRef]

6. Tolosa, I.; Garciandía, F.; Zubiri, F.; Zapirain, F.; Esnaola, A. Study of mechanical properties of AISI 316 stainless steel processed by "selective laser melting", following different manufacturing strategies. Int. J. Adv. Manuf. Technol. 2010, 51, 639-647. [CrossRef]

7. Kurzynowski, T.; Gruber, K.; Stopyra, W.; Kuźnicka, B.; Chlebus, E. Correlation between process parameters, microstructure and properties of $316 \mathrm{~L}$ stainless steel processed by selective laser melting. Mater. Sci. Eng. A 2018, 718, 64-73. [CrossRef] 
8. Zhang, J.; Song, B.; Wei, Q.; Bourell, D.; Shi, Y. A review of selective laser melting of aluminum alloys: Processing, microstructure, property and developing trends. J. Mater. Sci. Technol. 2019, 35, 270-284. [CrossRef]

9. Buchbinder, D.; Schleifenbaum, H.; Heidrich, S.; Meiners, W.; Bültmann, J. High Power Selective Laser Melting (HP SLM) of aluminum parts. Phys. Procedia 2011, 12, 271-278. [CrossRef]

10. Louvis, E.; Fox, P.; Sutcliffe, C.J. Selective laser melting of aluminium components. J. Mater. Process. Technol. 2011, 211, 275-284. [CrossRef]

11. Rometsch, P.; Jia, Q.; Yang, K.V.; Wu, X. Aluminum alloys for selective laser melting-Towards improved performance. Addit. Manuf. Aerosp. Ind. 2019, 301-325. [CrossRef]

12. Trevisan, F.; Calignano, F.; Lorusso, M.; Pakkanen, J.A.; Aversa, A.; Ambrosio, E.P.; Lombardi, M.; Fino, P.; Manfredi, D. On the Selective Laser Melting (SLM) of the AlSi10Mg alloy: Process, microstructure, and mechanical properties. Materials 2017, 10, 76. [CrossRef]

13. Li, Y.; Gu, D. Parametric analysis of thermal behavior during selective laser melting additive manufacturing of aluminum alloy powder. Mater. Des. 2014, 63, 856-867. [CrossRef]

14. Yap, C.Y.; Chua, C.K.; Dong, Z.; Liu, Z.H.; Zhang, D.Q.; Loh, L.E.; Sing, S.L. Review of selective laser melting: Materials and applications. Appl. Phys. Rev. 2015, 2, 041101. [CrossRef]

15. Jia, Q.; Rometsch, P.; Cao, S.; Zhang, K.; Wu, X. Towards a high strength aluminium alloy development methodology for selective laser melting. Mater. Des. 2019, 174, 107775. [CrossRef]

16. Aboulkhair, N.T.; Simonelli, M.; Parry, L.; Ashcroft, I.; Tuck, C.; Hague, R. 3D printing of aluminium alloys: Additive manufacturing of aluminium alloys using selective laser melting. Prog. Mater. Sci. 2019, 106, 100578. [CrossRef]

17. Aboulkhair, N.T.; Everitt, N.M.; Maskery, I.; Ashcroft, I.; Tuck, C. Selective laser melting of aluminum alloys. MRS Bull. 2017, 42, 311-319. [CrossRef]

18. Yakout, M.; Elbestawi, M.A.; Veldhuis, S.C. On the characterization of stainless steel 316L parts produced by selective laser melting. Int. J. Adv. Manuf. Technol. 2018, 95, 1953-1974. [CrossRef]

19. Li, R.; Shi, Y.; Wang, Z.; Wang, L.; Liu, J.; Jiang, W. Densification behavior of gas and water atomized 316L stainless steel powder during selective laser melting. Appl. Surf. Sci. 2010, 256, 4350-4356. [CrossRef]

20. Baitimerov, R.; Lykov, P.; Zherebtsov, D.; Radionova, L.; Shultc, A.; Prashanth, K.G. Influence of powder characteristics on processability of AlSi12 alloy fabricated by selective laser melting. Materials 2018, 11, 742. [CrossRef]

21. Muñiz-Lerma, J.A.; Nommeots-Nomm, A.; Waters, K.E.; Brochu, M. A Comprehensive approach to powder feedstock characterization for powder bed fusion additive manufacturing: A case study on AlSi7Mg. Materials 2018, 11, 2386. [CrossRef] [PubMed]

22. Spierings, A.B.; Voegtlin, M.; Bauer, T.; Wegener, K. Powder flowability characterisation methodology for powder-bed-based metal additive manufacturing. Prog. Addit. Manuf. 2015, 1, 9-20. [CrossRef]

23. Brika, S.E.; Letenneur, M.; Dion, C.A.; Brailovski, V. Influence of particle morphology and size distribution on the powder flowability and laser powder bed fusion manufacturability of Ti-6Al-4V alloy. Addit. Manuf. 2020, 31, 100929. [CrossRef]

24. Tonelli, L.; Liverani, E.; Valli, G.; Fortunato, A.; Ceschini, L. Effects of powders and process parameters on density and hardness of A357 aluminum alloy fabricated by selective laser melting. Int. J. Adv. Manuf. Technol. 2019, 106, 371-383. [CrossRef]

25. Garboczi, E.; Hrabe, N. Particle shape and size analysis for metal powders used for additive manufacturing: Technique description and application to two gas-atomized and plasma-atomized Ti64 powders. Addit. Manuf. 2020, 31, 100965. [CrossRef]

26. Nalivaiko, A.Y.; Arnautov, A.N.; Zmanovsky, S.V.; A Gromov, A. Al-Si-Cu and Al-Si-Cu-Ni alloys for additive manufacturing: Composition, morphology and physical characteristics of powders. Mater. Res. Express 2019, 6, 086536. [CrossRef]

27. Nalivaiko, A.Y.; Ozherelkov, D.Y.; Arnautov, A.N.; Zmanovsky, S.V.; Osipenkova, A.A.; Gromov, A.A. Selective laser melting of aluminum-alumina powder composites obtained by hydrothermal oxidation method. Appl. Phys. A 2020, 126, 871. [CrossRef]

28. Lee, Y.; Gurnon, A.K.; Bodner, D.; Simunovic, S. Effect of particle spreading dynamics on powder bed quality in metal additive manufacturing. Integr. Mater. Manuf. Innov. 2020, 9, 410-422. [CrossRef]

29. Engeli, R.; Etter, T.; Hövel, S.; Wegener, K. Processability of different IN738LC powder batches by selective laser melting. J. Mater. Process. Technol. 2016, 229, 484-491. [CrossRef]

30. Cherkasova, M.V.; Samukov, A.D.; Dmitriev, S.V.; O Mezenin, A. Research and engineering by REC "Mechanobr-technika" of additive technologies. J. Phys. Conf. Ser. 2021, 1721, 012025. [CrossRef]

31. Dmitriev, S.V.; Grigoryev, I.V. Prospects for the use of dielectric barrier discharge in electrostatic separation. Obogashchenie Rud 2018, 4, 34-37. [CrossRef]

32. Mezenin, A.; Dmitriev, S.; Cherkasova, M. Vibration effects in conditioning of metal powders. Vibroeng. Procedia $2019,25,36-41$. [CrossRef]

33. Gromov, A.A.; Nalivaiko, A.Y.; Ambaryan, G.N.; Vlaskin, M.S.; Buryakovskaya, O.A.; Kislenko, S.A.; Zhuk, A.Z.; Shkolnikov, E.I.; Slyusarskiy, K.V.; Osipenkova, A.A.; et al. Aluminum-alumina composites: Part I: Obtaining and characterization of powders. Materials 2019, 12, 3180. [CrossRef] [PubMed] 